\title{
Temperature regime studies and mathematical calculations for dry snow covers in the western Tien Shan mountains, Ghina
}

\author{
Ma Hong, Liu ZongchaO \\ Xinjiang Institute of Geography, Academia Sinica, Ürümqi 830011, China \\ AND YANG ZHIAN \\ Department of Physics, Xinjiang University, Ürümqi 830046, China
}

\begin{abstract}
A mathematical model is proposed to simulate the spatial and temporal variations in snow temperature. The model is based on the non-steady, onedimensional, heat-conduction equation with internal heat source. It gives the change in time of the internal temperature field of the snow as it responds to varying surface temperature and periodic solar radiation. Verification of the model is accomplished by comparing the calculated results with observed data. The model may serve as a basis for quantitative investigations of snow temperature and temperature gradient, and relevent problems such as energy-mass transfer processes. Moreover, it allows better understanding of the relationship between external atmospheric conditions and the internal thermal regime of dry snow covers in the western Tien Shan mountains.
\end{abstract}

\section{INTRODUCTION}

The seasonal snow cover in the western Tien Shan mountains (Chinese portion) is characterized by low density, low liquid-water content, and low temperature. Because of the geographical location and the continental climate, it differs greatly in physical properties from the wet snow which forms under maritime climate conditions. The large temperature gradient and extremely welldeveloped depth hoar observed in the basal layers of the snow covers in this area have long been of interest in avalanche studies, because the formation of depth hoar was thought to be responsible for avalanche release. Observations and field experiments suggest that high temperature gradients play a dominant role in the process of depth hoar formation. Thus, considerable attention has been paid to the study of temperature distribution in snow in order to examine the relationship between temperature gradient and processes of heat transfer, vapour migration, snow-crystal growth, and the influence of external atmospheric conditions on the thermal regime of snow.

Scientific studies of the thermal regime of dry snow in the western Tien Shan mountains date back to the 1970 s (Zhang, 1987; Xie Zichu and Ma Zhenghai, unpublished reports, 1973). Detailed studies on various aspects of physical properties of dry snow have been carried out mainly since 1980 (Zhang, 1987; Zhu Qian, unpublished report, 1987; Liu and others, 1988, Wang, 1989). In these studies, much work has been devoted to the analysis of snow temperature through field observations and experi- ments. However, most studies have focused on individual problems, and there has been no attempt to incorporate these individual aspects into a simulation model to describe the temperature regime of dry snow.

This paper will first review some previous Chinese studies on radiation and thermal properties of dry snow, as well as some field observations. Secondly, a mathematical model is developed which incorporates some results from these studies. Then, thirdly, the model is tested against measured data from a snow cover in the midmountain zone of the western Tien Shan mountains.

\section{PREVIOUS STUDIES}

\section{Solar radiation penetration}

Liu and others (1988) studied the penetration of solar radiation into dry snow using EKO series radiometers at the Tien Shan Snow and Avalanche Research (TSAR) Station ( lat $43^{\circ} 16^{\prime} \mathrm{N}$, long $84^{\circ} 24^{\prime} \mathrm{E} ; 1776 \mathrm{~m}$ a.s.l.) of the Xinjiang Institute of Geography, Chinese Academy of Sciences. The results showed that the penetration of solar radiation into the snow follows the law of absorption:

$$
I(x)=I_{0} e^{-\mu x} \quad\left(\mathrm{~W} \mathrm{~m}^{-2}\right) .
$$

For different snow densities from 150 to $250 \mathrm{~kg} \mathrm{~m}^{-3}$, the measured values of $\mu$ tended to a constant which is approximately $0.13 \mathrm{~cm}^{-1}$. This means that $72.5 \%$ of the penetrating solar radiation is absorbed in $0.10 \mathrm{~m}, 92.6 \%$ 
is absorbed in $0.20 \mathrm{~m}$, and over $98.0 \%$ of the penetrating solar radiation is absorbed in $0.30 \mathrm{~m}$ depth beneath the snow surface. The significant depth of penetrating solar radiation on snow temperature is about $0.20 \mathrm{~m}$. When solar radiation penetrates the surface and is absorbed in snow, it functions as an internal heat source which raises the snow temperature. Thus, it is considered to be an important factor in determining the thermal regime of the snow cover.

\section{Effective thermal conductivity}

Wang (1989) at the same experimental site near the TSAR Station studied the effective thermal conductivity of dry snow. The results showed that the effective thermal conductivity $k$ of dry snow in the western Tien Shan mountains is proportional to the density of snow and to the $\frac{3}{2}$ power of mean grain size. The empirical expression is

$$
k=37.37 \rho \bar{\varphi}^{\frac{3}{2}} . \quad\left(\mathrm{W} \mathrm{m}^{-1}{ }^{\circ} \mathrm{C}^{-1}\right) .
$$

Under conditions of densification and snow-crystal growth, $k$ varies directly with the second power of snow density.

\section{Thermal conditions at snow surfaces}

Ealier measurements of snow temperature profiles in the western Tien Shan mountains were made mainly in open, flat areas, because snow-surface temperature is closely associated with the periodic solar radiation. So it varies periodically and can be described by means of a sinusoidal function. As for the temperature at the snowsoil interface, field measurements showed that it varies between 0 and $-1.5^{\circ} \mathrm{C}$ at an open, flat site (Ding Shaoxiang, unpublished report, 1973), and between 0 and $-5^{\circ} \mathrm{C}$ at a shaded, flat site (Zhang, 1987), throughout winter. The maximum daily deviation from the average temperature at the snow-soil interface was less than $\pm 0.3^{\circ} \mathrm{C}$ if the thickness of snow exceeds $30 \mathrm{~cm}$ (Liu and others, 1988). The average multi-year snow depth recorded at the TSAR Station is $84 \mathrm{~cm}$ with a coefficient of variation less than 0.2 . These results suggest that the temperature at the bottom surface of snow covers in these mountains is nearly constant and close to $0^{\circ} \mathrm{C}$.

\section{MODEL DESCRIPTION AND SOLUTIONS}

Based on previous studies mentioned above, the thermal state of a seasonal snow cover can be determined by application of the law of conservation and conversion of energy, in the form of the non-steady, one-dimensional, heat-conduction equation with internal heat source, together with the initial and boundary conditions

$$
\begin{gathered}
\frac{\partial T(x, t)}{\partial t}=\alpha \frac{\partial^{2} T(x, t)}{\partial x^{2}}+\frac{\mu}{\rho c} I(t) e^{-\mu\left(X_{0}-x\right)} \\
T(0, t)=T_{0} \\
T\left(X_{0}, t\right)=\bar{T}+A_{\mathrm{s}} \sin (\omega t-\theta)
\end{gathered}
$$

$$
T(x, 0)=A+B x+C x^{2}
$$

where $T(x, t)$ is the temperature at any thickness $x$ and at any time $t, \alpha=k / \rho c$ is the thermal diffusivity of snow, $k$ is the thermal conductivity, $\rho$ is the snow density, $c$ is its specific heat, $\mu$ is the radiation absorption constant of snow, $I(t)$ is the penetrating solar radiation at any time $t, X_{0}$ is the snow thickness, $t$ is time, and $x$ is the vertical coordinate with its origin at the base of the snow and is positive upwards.

The upper boundary condition (5) is determined by a sinusoidal function as

$$
f(t)=\bar{T}+A_{\mathrm{s}} \sin (\omega t-\theta),
$$

where $\bar{T}$ is the average daily surface temperature of snow, $A_{\mathrm{s}}$ is the amplitude of the surface temperature fluctuation, $\omega$ is the angle frequency, and $\theta$ is the initial phase which is determined by lag time between the radiation peak and surface-temperature peak. The lower boundary condition $T_{0}$ is treated here as a constant because the daily variation of snow temperature at the bottom surface is negligible.

The initial condition (6) is derived from the initial distribution of temperature in snow by fitting a polynomial

$$
g(x)=A+B x+C x^{2}
$$

where $A, B$, and $C$ are, respectively, the fitting coefficients of Equation (8).

Radiation boundary conditon $I(t)$ is given in terms of the Fourier series as

$$
I(t)=\frac{I_{0}}{\pi}+\frac{I_{0}}{2} \sin \omega t+\frac{2 I_{0}}{\pi} \sum_{\mathrm{m}=1}^{\infty} \frac{1}{1-(2 m)^{2}} \cos 2 m \omega t,
$$

where $I_{0}$ is the peak of penetrating solar radiation at the snow surface.

Together with the initial and boundary conditions, Equation (3) can be solved using the familiar Fourier series approach. The solution is

$$
\begin{aligned}
T(x, t)=T_{0}+ & \frac{\left[f(t)-T_{0}\right] x}{X_{0}}+\sum_{n=1}^{\infty}\left\{\frac{2}{n \pi}\left[f(0)(-1)^{n}-T_{0}\right]\right. \\
+ & \frac{2(-1)^{n}}{n \pi} \int_{0}^{t} \mathrm{e}^{\left(\frac{n \pi}{X_{0}}\right)^{2} \alpha \tau} \frac{\mathrm{d} f(\tau)}{\mathrm{d} \tau} \mathrm{d} \tau \\
+ & \frac{2}{X_{0}} \int_{0}^{X_{0}} g(x) \sin \frac{n \pi}{X_{0}} x \mathrm{~d} x \\
+ & \frac{2 n \pi \mu\left[\mathrm{e}^{-\mu X_{0}}-(-1)^{n}\right]}{\rho c\left(\mu^{2} X_{0}^{2}+n^{2} \pi^{2}\right)} \\
& \left.\int_{0}^{t} I(\tau) \mathrm{e}^{\left(\frac{n \pi}{X_{0}}\right)^{2} \alpha \tau} \mathrm{d} \tau\right\} \mathrm{e}^{-\left(\frac{n \pi}{X_{0}}\right)^{2} \alpha t} \sin \frac{n \pi}{X_{0}} x .
\end{aligned}
$$

The temperature gradient is then obtained by differentiation of Equation (10)

$$
\begin{gathered}
G(x, t)=\frac{\left[f(t)-t_{0}\right]}{X_{0}}+\sum_{n=1}^{\infty}\left\{\frac{2}{n \pi}\left[f(0)(-1)^{n}-T_{0}\right]\right. \\
+\frac{2(-1)^{n}}{n \pi} \int_{0}^{t} \mathrm{e}^{\left(\frac{n \pi}{X_{0}}\right)^{2} \alpha \tau} \frac{\mathrm{d} f(\tau)}{\mathrm{d} \tau} \mathrm{d} \tau
\end{gathered}
$$




$$
\begin{aligned}
&+\frac{2}{X_{0}} \int_{0}^{X_{0}} g(x) \sin \frac{n \pi}{X_{0}} x \mathrm{~d} x \\
&\left.+\frac{2 n \pi \mu\left[\mathrm{e}^{-\mu X_{0}}-(-1)^{n}\right]}{\rho c\left(\mu^{2} X_{0}^{2}+n^{2} \pi^{2}\right)} \int_{0}^{t} I(\tau) \mathrm{e}^{\left(\frac{n \pi}{X_{0}}\right)^{2} \alpha \tau} \mathrm{d} \tau\right\} \\
& \frac{n \pi}{X_{0}} \mathrm{e}^{-\left(\frac{n \pi}{X_{0}}\right)^{2} \alpha t} \cos \frac{n \pi}{X_{0}} x
\end{aligned}
$$

The respective solutions of Equations (10) and (11) give the change in time and space of the temperature and temperature gradient in snow. The integral terms in Equations (10) and (11) can be solved with the given initial and boundary conditions in Equations (7) and (9).

The basic assumptions involved in the development of the model are listed below:

(1) The snow cover is idealized as a rigid porous medium, and changes in density, and, therefore, in thermal properties, are neglected.

(2) Heat and mass transfer in the snow cover are onedimensional.

(3) Physical and thermal properties of snow can be represented by empirical relations adopted.

(4) The process of meltwater infiltration is not considered, so the model is not valid during the snowmelt period.

(5) Clear skies and stable weather conditions only are considered in developing the model. Otherwise, the boundary conditions cannot be accurately determined in the forms of Equations (7) and (9).

\section{MODEL RESULTS AND DISGUSSION}

The model is tested with a set of observed data from a snow-covered site (site A) located on a south-facing slope of about $7^{\circ}$ near the TSAR Station. The date of 16 February 1987 is selected for model verification. On 16 February, it was clear and no surface melting was observed. The recorded mean daily air temperature and wind velocity from the nearby weather station $(50 \mathrm{~m}$ apart from site A) were $-9.8^{\circ} \mathrm{C}$ and $2.0 \mathrm{~m} \mathrm{~s}^{-1}$, respectively.

The snow-temperature profiles were measured hourly using the HP-3479A Digital Data Collection System; the sensors of the system were mounted above the snow-soil interface at $10 \mathrm{~cm}$ intervals. The components of radiation were also measured hourly using the EKO series radiometers, at a height of $1.5 \mathrm{~m}$ above the snow surface. On 16 February, the measured incoming solar radiation was $464 \mathrm{~W} \mathrm{~m}^{-2}$ at $1200 \mathrm{~h}$ (local solar time), and the albedo of the snow surface was 0.86 , so the peak value of the penetrating radiation at the snow surface $I_{0}$ was found to be $65.0 \mathrm{~W} \mathrm{~m}^{-2}$. From the initial distribution of temperature in snow, the fitted coefficients for the initial condition $g(x)$ were, respectively, $A=-0.5^{\circ} \mathrm{C}$ $B=5.25^{\circ} \mathrm{C} \mathrm{m}^{-1}$, and $C=-47.67^{\circ} \mathrm{C} \mathrm{m}^{-2}$. The following parameters were also measured: $\bar{T}=-8.0^{\circ} \mathrm{C}, A_{\mathrm{s}}=$ $7.6^{\circ} \mathrm{C}$, and $T_{0}=-0.5^{\circ} \mathrm{C}$.

The thickness of the snow cover was $0.6 \mathrm{~m}$, with an average snow density of $220 \mathrm{~kg} \mathrm{~m}^{-3}$. The adopted specific heat capacity of snow $c=0.58 \mathrm{~W} \mathrm{~h}^{-1} \mathrm{~kg}^{-1}{ }^{\circ} \mathrm{C}^{-1}$. Because data of snow-grain size are lacking, the effective thermal conductivity of snow is calculated as

$$
k=2.09 \times 10^{-5}+D \rho^{2} \quad\left(\mathrm{~kW} \mathrm{~m}^{-1}{ }^{\circ} \mathrm{C}^{-1}\right)
$$

(Anderson, 1976), where $\rho$ is the snow density and $D$ is about $2.5 \times 10^{-9}$ for seasonal snow cover. From Equation (12) the thermal effective conductivity $k$ is $0.13 \mathrm{~W} \mathrm{~m}^{-1}$ ${ }^{\circ} \mathrm{C}^{-1}$ for a snow density of $220 \mathrm{~kg} \mathrm{~m}^{-3}$ and the thermal diffusivity $\alpha$ is found to be $1.11 \times 10^{-3} \mathrm{~m}^{2} \mathrm{~h}^{-1}$. By substituting these parameters into Equations (10) and (11), the temperature and temperature-gradient profiles are calculated, and the results are shown in Figures 1 and 2 , respectively.

The calculated results of snow temperature are compared with the measured data at 3-hour intervals (Table 1). As seen in this table, there is a good agreement between the calculated and measured values. Differences occur mainly in the top layers of the snow cover; this seems mainly due to the errors in fitting the upper boundary condition (Equation (7)), a sinusoidal surface temperature cycle. Figure 3 shows an observed snowsurface temperature curve and a fitted one, both for 16 February. From this figure, the maximum surface temperature observed lags the radiation peak by 1 or 2 hours, while the lowest surface temperature occurs just before the sunrise instead of at midnight or 1 or 2 hours after that. Because of this, if higher precision results are desired from the model, further studies are required to improve the accuracy in fitting the upper boundary condition in Equation (7).

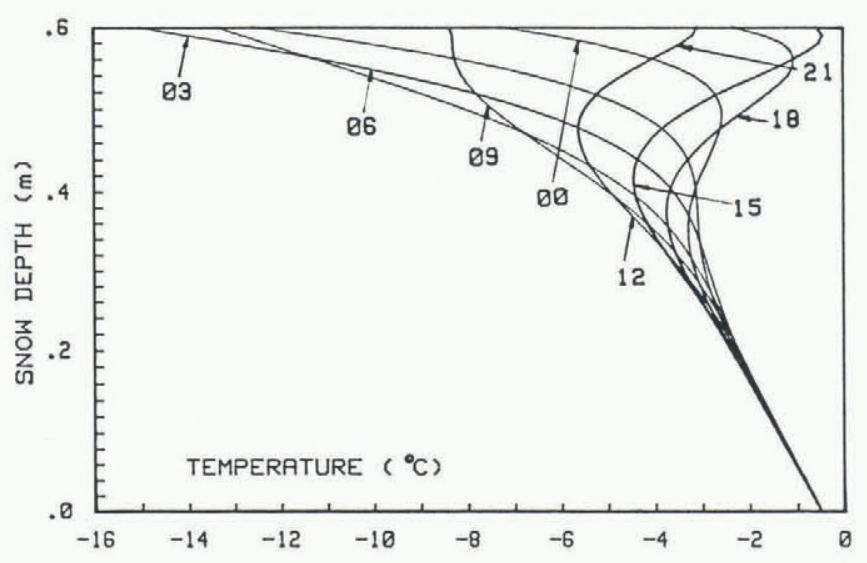

Fig. 1. Temperature profiles calculated from the model for site A, 16 February 1987. Time is given in hours of local solar time.

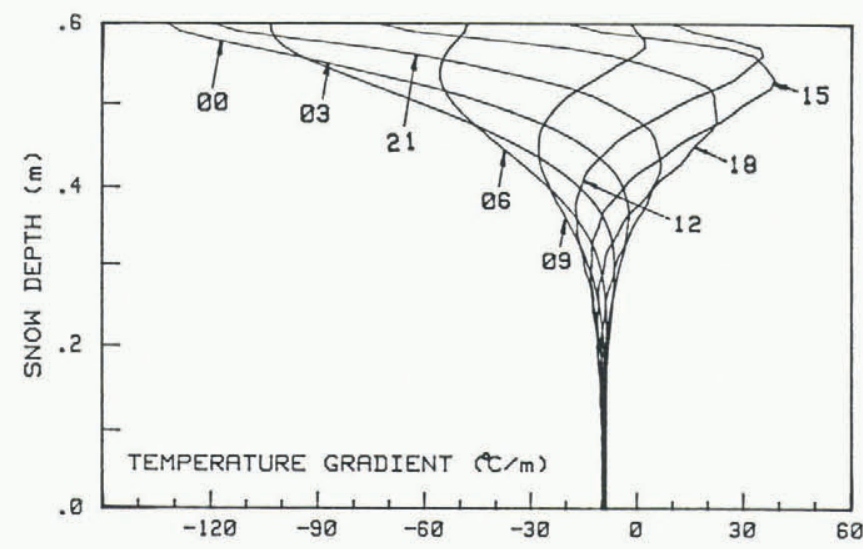

Fig. 2. Temperature gradient profiles calculated from the model for site A, 16 February 1987. Time is given in hours of local solar time. 
Ma Hong and others: Temperature of dry snow in western Tien Shan

Table 1. Comparison of calculated $\left(T_{\mathrm{c}}\right)$ and measured $\left(T_{\mathrm{m}}\right)$ snow temperatures $\left({ }^{\circ} \mathrm{C}\right)$

\begin{tabular}{|c|c|c|c|c|c|c|c|c|c|c|c|c|c|c|c|c|}
\hline \multirow{2}{*}{$\begin{array}{l}\text { Snow } \\
\text { depth } \\
\mathrm{m}\end{array}$} & \multicolumn{2}{|c|}{$06: 00$} & \multicolumn{2}{|c|}{$09: 00$} & \multicolumn{2}{|c|}{$12: 00$} & \multicolumn{2}{|c|}{$15: 00$} & \multicolumn{2}{|c|}{$18: 00$} & \multicolumn{2}{|c|}{ 21:00 } & \multicolumn{2}{|c|}{$00: 00$} & \multicolumn{2}{|c|}{ 03:00 } \\
\hline & $T_{\mathrm{m}}$ & $T_{\mathrm{c}}$ & $T_{\mathrm{m}}$ & $T_{\mathrm{c}}$ & $\tau_{\mathrm{m}}$ & $T_{\mathrm{c}}$ & $T_{\mathrm{m}}$ & $T_{\mathrm{c}}$ & $\mathcal{T}_{\mathrm{m}}$ & $T_{\mathrm{c}}$ & $T_{\mathrm{m}}$ & $T_{\mathrm{c}}$ & $T_{\mathrm{m}}$ & $T_{\mathrm{c}}$ & $T_{\mathrm{m}}$ & $T_{\mathrm{c}}$ \\
\hline 0.6 & -12.5 & -13.5 & -8.3 & -8.3 & -0.7 & -2.8 & -0.4 & -0.3 & -7.6 & -2.7 & -9.1 & -7.3 & -11.1 & -12.2 & -13.3 & -14.6 \\
\hline 0.5 & -9.1 & -10.7 & -8.6 & -9.1 & -3.8 & -5.6 & -2.7 & -2.4 & -4.6 & -4.6 & -5.4 & -4.4 & -6.4 & -5.4 & -7.4 & -6.9 \\
\hline 0.4 & -4.8 & -5.7 & -4.7 & -6.0 & -4.3 & -5.3 & -3.8 & -4.1 & -4.0 & -5.1 & -3.7 & -4.6 & -3.8 & -4.4 & -4.2 & -4.3 \\
\hline 0.3 & -2.7 & -3.0 & -3.2 & -3.3 & -3.3 & -3.3 & -3.2 & -3.2 & -3.0 & -3.2 & -2.7 & -3.1 & -2.9 & -3.1 & -3.0 & -3.0 \\
\hline 0.2 & -1.8 & -1.8 & -1.9 & -1.9 & -2.0 & -2.0 & -2.0 & -2.1 & -2.1 & -2.1 & -2.1 & -2.0 & -1.9 & -1.9 & -1.9 & -2.0 \\
\hline 0.1 & -1.0 & -1.1 & -1.0 & -1.1 & -1.0 & -1.1 & -1.0 & -1.2 & -1.0 & -1.2 & -1.0 & -1.2 & -1.1 & -1.2 & -1.1 & -1.1 \\
\hline 0.0 & -0.5 & -0.5 & -0.5 & -0.5 & -0.5 & -0.5 & -0.5 & -0.5 & -0.5 & -0.5 & -0.5 & -0.5 & -0.5 & -0.5 & -0.5 & -0.5 \\
\hline
\end{tabular}

The impinging solar radiation at the snow surface is simulated and compared wtih the data observed. The close agreement bwetween them (Fig. 4) indicates a good representation of impinging solar radiation provided by Equation (9) under clear-sky conditions.

The model shows that significant diurnal variations in snow temperature only occur in the top layers of the snow

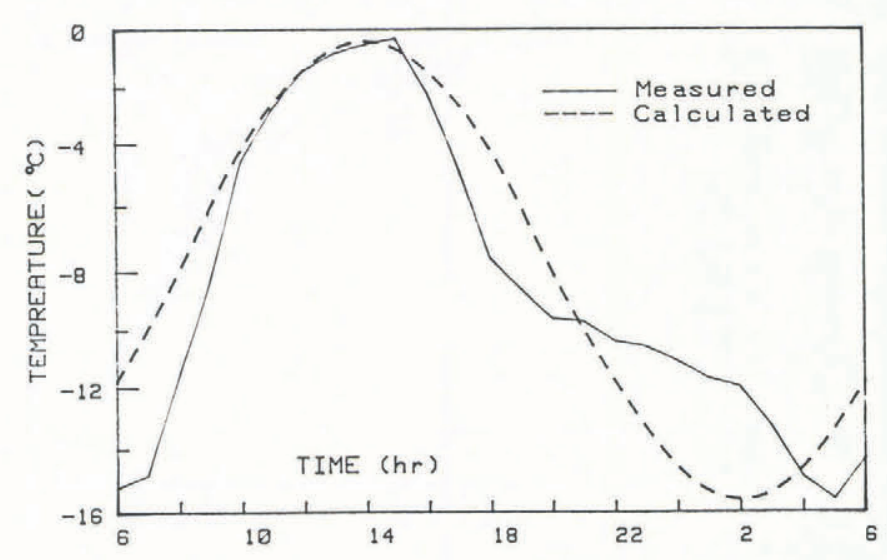

Fig. 3. Comparison of measured (solid line) and fitted (dashed line) snow surface temperature for site $A, 16$ February 1987.

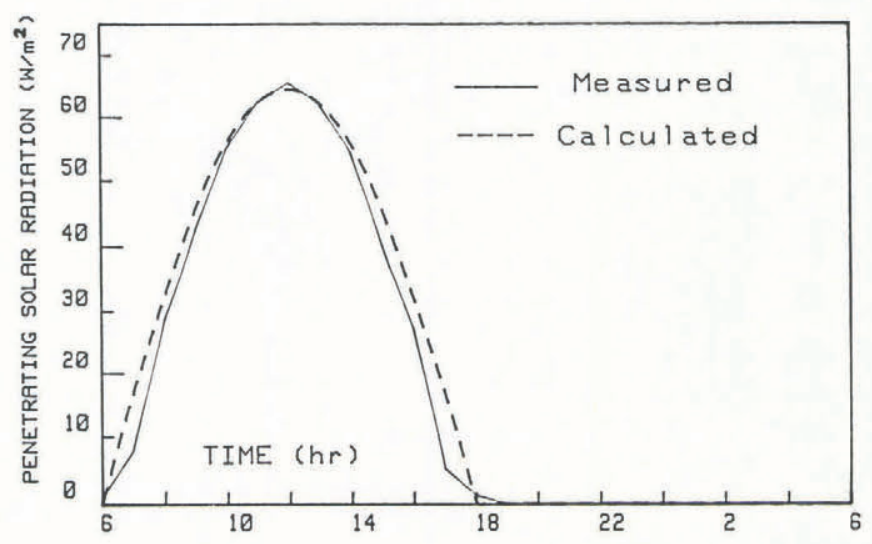

Fig. 4. Comparison of measured (solid line) and fitted (dashed line) penetrating solar radiation at the snow surface for site A, 16 February 1987. cover, at a depth of about $20 \mathrm{~cm}$ below the surface (Fig. $1)$, while the temperature in the basal layer is comparatively stable in spite of the large temperature fluctuation and strong solar radiation at the snow surface. The same is true of the temperature gradients (Fig. 2). These correspond to the real cases described by Zhang (1987) as the results of field observations.

In central areas of the western Tien Shan mountains, the temperature gradient in the basal layers of snow cover usually forms in early December, when snow thickness increases to a basic value of at least $30 \mathrm{~cm}$, and ends at the beginning of the snowmelt period, when the snow becomes isothermal at $0^{\circ} \mathrm{C}$. Throughout this long period of about 4 or 5 months, the temperature gradient is relatively stable in its magnitude and direction. This has long been noticed and thought to be responsible for depth-hoar formation. A mechanism, which has long been observed by Chinese colleagues, is that depth-hoar formation in the western Tien Shan mountains is attributed to vapour diffusion only within the snow. But one more fact can be seen as a result of the model study. For example, on 16 February, the average daily temperature gradient at the snow-soil interface calculated from the model is $-8.9^{\circ} \mathrm{Cm}^{-1}$, which indicates a corresponding ground heat flux of $1.8 \mathrm{~W} \mathrm{~m}^{-2}$ into the snow cover. This implies the existence of vapour flux migrating from the underlying ground to the snow cover because water-vapour gradient is similar to that of temperature.

The effect of solar-radiation penetration on the thermal regime of snow has been discussed in detail by Colbeck (1989). He reached the conclusion that the amount of solar radiation absorbed beneath the surface of a snow cover can introduce more energy into the snow than can be readily conducted. Therefore, the sub-surface temperature becomes higher than it would be in the absence of solar input. To show this experimentally, the snow-temperature profiles (Fig. 5) at experimental site B were measured simultaneously with those measured at site A. Site B is located on a flat terrace shaded entirely by mountains, $60 \mathrm{~m}$ apart from site A. Clearly, the penetrating solar radiation shifts the temperature near the surface from lower values shown in Figure 5 to higher values shown in Figure 1 during the day-time. It seems 


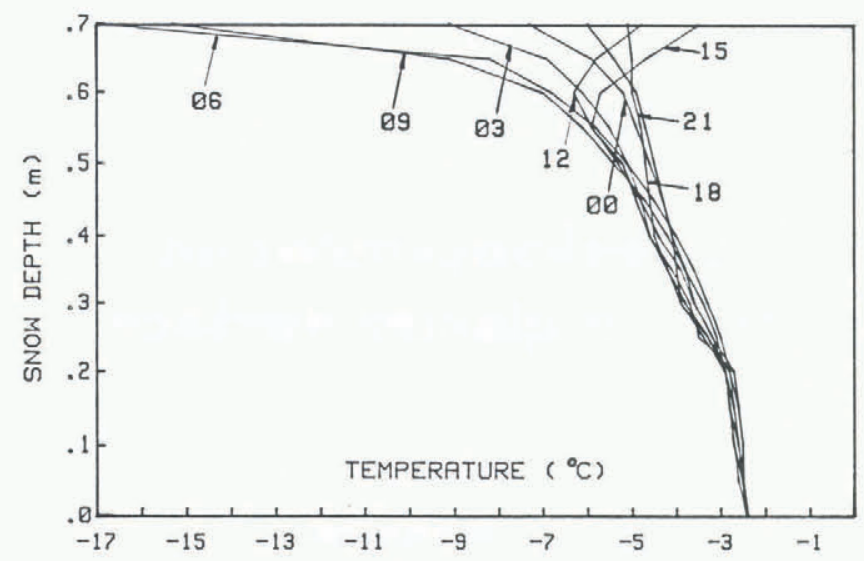

Fig. 5. Temperature profiles measured at site B, 16 February 1987. Time is given in hours of local solar time.

that there is no effect of solar input on snow temperature in the basal layers because there is no noticeable variation in temperature between the day and night. However, while radiation penetration increases the average temperature and temperature gradient just below the surface, it decreases the average temperature gradient in an intermediate layer below that (Colbeck, 1989). The effect of this is to decrease the heat loss from the basal layers, and, hence, to increase the temperature in the basal layers of the snow cover. From Figure 1 and Figure 5, for example, the temperatures at the snow-soil interfaces of site $\mathrm{A}$ and site $\mathrm{B}$ were, respectively, $-0.5^{\circ} \mathrm{C}$ and $-2.7^{\circ} \mathrm{C}$, and the measured thicknesses of frozen soil underlying the two snow covers were, respectively, 25 and $75 \mathrm{~cm}$. These differences are considered to be due to the effects of solar radiation because the two sites were under the same external conditions except for the solar radiation received. From this it can be seen that the solar radiation affects snow temperature, not only in the upper layers of a snow cover, but also in deeper layers. This is not because the solar radiation penetrates to the deeper layers and heats the snow by absorption (because the penetrating solar radiation only reaches a limited depth of about $30 \mathrm{~cm}$ below the snow surface), but because the penetrating solar radiation warms the snow near the surface and decreases the average temperature gradient below that.
This decreased temperature gradient allows more heat energy to be accumulated and less to be lost, and, therefore, increases the temperature in the deeper layers of the snow cover, or even in the underlying frozen ground.

\section{CONGLUSIONS}

A mathematical model has been developed for simulating temperature and temperature gradient in dry snow covers. The model is based on sound physical principles and gives results which are consistent with the observed data. Although the model presented seems too complex for application, and some defects need improving, it may be considered as a useful tool to investigate various physical processes in snow. One of the advantages offered by this model is that it not only permits a quantitative description of temperature regime in snow, but also related it to external conditons. This allows a better understanding of relationship between the thermal regime of the snow cover and external atmospheric conditions, from a theoretical perspective.

\section{REFERENCES}

Anderson, E. A. 1976. A point energy and mass balance model of a snow cover. NOAA Tech. Rep. NWS 19.

Colbeck, S. C. 1989. Snow-crystal growth with varying surface temperatures and radiation penetration. $\mathcal{F}$. Glaciol., 35(119), 23-29.

Liu Zongchao, Cai Guotang and Sun Li. 1988. Radiation properties of seasonal snow in the western Tien Shan mountains. Arid Land Geography, 11(2), 73-80.

Wang Guo. 1989. A model of effective thermal conductivity of dry snow. Arid Land Geography (Special Issue) No. 1, 141-146.

Zhang Zhizhong. 1987. Preliminary research on temperature regime in seasonal snow cover and its relation to frost penetration depth in Gangnaisi valley, Tien Shan mountains. F. Glaciol. Geocryol., 9(1), 69-79. [In Chinese with English summary.]

The accuracy of references in the text and in this list is the responsibility of the author/s, to whom queries should be addressed. 